\title{
Cloning and Expression of the Human Extracellular Superoxide Dismutase (EC-SOD) Gene in Probiotic Lactobacillus Casei
}

\author{
Chuan-Mu Chen, Zi-Lun Lai, Chih-Ching Yen, Miao-Ling Wang, and Hsiao-Ling Chen
}

\begin{abstract}
Reactive oxygen species (ROS) have been implicated in a number of disease processes. Oxidative stress is inhibited by enzymatic defense mechanisms, such as superoxide dismutase, catalase, and glutathione peroxidase. Extracellular superoxide dismutase (EC-SOD or SOD3) is an antioxidant enzyme secreted by cells to prevent overproduction of reactive oxygen species. It could potentially be used to prevent and cure cardiovascular disease, neurological disorders, and inflammation resulting from the accumulation of superoxide anions. In this study,we expressed the EC-SOD gene isolated from a human aortic smooth muscle cDNA library in food-grade Lactobacillus caseiCCRC10679. We used an 18-aa signal peptide from human SOD3 (hSOD3) to mediate extracellular secretion. After electroporation and 20 rounds of erythromycin antibiotic selections, two clones were isolated that expressed high levels of recombinant EC-SOD. The recombinant protein was purified from L.casei/hSOD3 using fast protein liquid chromatography (FPLC) with a heparin affinity column. The purified enzyme showed two bands at 38kDa (monomer) and $76-\mathrm{kDa}$ (dimer) by SDS-PAGE and western blotting. The 76-kDa band was also detected by a nitrobluetetrazolium assay. Antioxidant activity of the purified EC-SOD was determined using a water-soluble tetrazolium (WST-1) assayto demonstrate that production of recombinant EC-SOD in the food-grade $L$. casei actually possessed enzymatic activity.
\end{abstract}

Index Terms-Extracellular superoxide dismutase (EC-SOD), Lactobacillus casei, signal peptide, heparin, antioxidant.

\section{INTRODUCTION}

Superoxide dismutase (SOD) proteins are the key antioxidant enzymes in the metabolism of oxygen-free radicals. They catalyze the dismutation of superoxide anions to oxygen and hydrogen peroxide. There are three SODisozymes in mammaliancells that vary by the type of metal ion they bind to and their cellular localization. Copper and zinc-SOD (CuZn-SOD or SOD1) are found primarily in the cytoplasm and nucleus of cells [1],

Manuscript received May 3, 2013; revised July 15, 2013. This work was supported in part by grantNSC-100-2313-B-005-012 from the National Science Council.

Chuan-Mu Chen and Z. L. Lai are the Department of Life Sciences, National Chung Hsing University, No. 250 KuoKuang Road, Taichung 402 , Taiwan (e-mail: chchen1@dragon.nchu.edu.tw, ywlai@dns.dwvs.cy.edu.tw)

Hsiao-Ling Chen is with the Department of Bioresources, Da-Yeh University, No. 168 University Road, Changhwa 515, Taiwan (e-mail bellchen@mail.dyu.edu.tw).

C. C. Yen is with Department of Internal Medicine, China Medical University Hospital, Taichung, Taiwan (e-mail: davidcc@hotmail.com.tw).

M. L. Wang is with Department of Molecular Biotechnology, Da-Yeh University, Changhwa, Taiwan (e-mail: ling8091@yahoo.com.tw ).
manganese-SOD (Mn-SOD or SOD2) is found in the mitochondria [2], and extracellular-SOD (EC-SOD or SOD3) is found predominantly in the extracellular matrix of tissues. SOD3, a secretory tetrameric copper and zinc-containing glycoprotein, is highly expressed in lung and vascular tissues. It is also the major SOD in plasma, lymph, and synovial extracellular fluids [3].

EC-SOD is a multimeric glycoprotein found in extracellular fluids that is composed of at least four identical 30-kDa subunits with heterogeneous affinity for heparin [4]. EC-SOD exists in high concentrations in both systemic and pulmonary blood vessels and in airways. It may also be the dominant form of SOD in most arteries [5] and is present in both the adventitia and in the smoothmuscle cells surrounding blood vessels and airways [6]. EC-SOD may be the most important first line of defense for protecting cell surfaces and extracellular matrix proteins from superoxidemediated damages.

Every biological macromolecule is a potential target for oxygen radicals, so there is interest in the therapeutic potential of EC-SOD.Recently, a wide range of clinical applications have been suggested, including prevention of oncogenesis and tumor promotion [7], [8], reduction of the cytotoxic and cardiotoxic effects of anticancer drugs, and protection against reperfusion damage to ischemic tissues [9], [10].

Lactobacillus casei(L. casei) is a lactic acid bacterium (LAB). LABs are characterized as Gram-positive, nonsporulating, cocci or rodsshaped, catalase-lacking organisms. They are widespread in most natural environments, such as water, soil, plants, animals, food products and the human body, and are involved in many food fermentation processes, including yogurt, cheese, sausage, and bread production. Most LAB are generally regarded as safe (GRAS) and have been considered for use as probiotics. This distinction also allows them to be used as live vectors [11], [12].

The potential demand for EC-SOD in the human healthcare industry is large; therefore, large-scale production of biologically active EC-SOD is necessary. Production of therapeutic proteins by genetically engineered $\mathrm{LAB}$ is a cost-effective alternative to tissue cultures or purification of enzymes from animal tissues. We aimed to produce and purify recombinant EC-SOD with high antioxidant activity in L. casei. Expression of EC-SOD in probioticL. casei may be used to develop novel functional foods that serve as a first line of antioxidant defense.

\section{Materials And Methods}

\section{A. Construction, Screening, and Selection of EC-SOD Expression Plasmid Clones}


A full length human EC-SODcDNA (GenBank accession number: NM_003102) encoding 240 amino acids of the human EC-SOD polypeptide (GenBank accession number: NP_003093) was isolated and cloned from a human aortic smooth muscle cDNA library (Uni-ZAP XR system, Stratagene, La Jolla, CA, USA) using a three-round screening process. The recombinant $0.7-\mathrm{kb}$ mature human EC-SODcDNA fragment containing an 18-aa signal peptide was amplified by PCR using the following primers: SOD3NdeI (foreword) 5'-ACATATGCTGGCGCTTGTGTTCC-3' and SOD3-HindIII (reverse) 5'TAAGCTTCAGGCGGCCTTGCACT-3'. The underlined bases indicate the introduced restriction sites. The PCR product was cloned into the pGEM $^{\circledR}$-T easy vector using a T/A Cloning Kit (Promega, Madison, WI, USA), and the sequence was verified by nucleotide sequencing [13], [14].The resulting pGEM $^{\circledR}$-T-hSOD3 construct was digested with NdeI (New England Biolabs, Beverly, MA, USA) at the newly created sites, and the hSOD3 fragment was gel purified. The excised fragment was cloned in the pLP3537Lactobacillus expression vector system. This construct was termed "pLP3537-hSOD3".

The purified pLP3537-hSOD3 expression cassette was transformed into Lactobacillus casei CCRC10679 host cells. For electroporation, a 50-ml culture of L. casei CCRC10679 in de Man Rogosaand Sharpe(MRS) broth (Difico Laboratories, Detroci, MI, USA) was grown at $37^{\circ} \mathrm{C}$ to an $\mathrm{OD}_{600}$ of $0.6\left(\sim 2.3 \times 10^{7}\right.$ cells $\left./ \mathrm{ml}\right)$. Cells were washed twice and resuspended in $1.5 \mathrm{ml}$ of ice-cold sterilized deionized water.The competent $L$. casei CCRC10679 cells were mixed with $80 \mu \mathrm{l}$ of $10 \%$ glycerol and placed on ice for later use. An aliquot of competent $L$. casei CCRC10679 cells $(80 \mu \mathrm{l})$ was mixed with $10 \mu \mathrm{g}$ of pLP3537-hSOD3 DNA and transferred to an ice-cold 2-mm electroporation cuvette [15], [16]. The cells were pulsed according to the previously described parameters for L. casei CCRC10679 (2500 V, 25 $\mu \mathrm{F}$, and $200 \Omega$ ) [17]. The cells were incubated for $1 \sim 2 \mathrm{~h}$ at $37^{\circ} \mathrm{C}$ and then spread on MRS containing $5.0 \mu \mathrm{g} / \mathrm{ml}$ erythromycin (Sigma, St. Louis, MO, USA). Transformants were visible after $2-3$ days of culture at $37^{\circ} \mathrm{C}$. Several hundred erythromycin-resistant transformants were identified during the first round of selection. In the second round, multi-copy transformantswere selected by plating $L$. casei CCRC10679 transformants on mediacontaining 25, 50, and $100 \mu \mathrm{g}$ oferythromycin per $\mathrm{ml}$. Several transformantsthat were resistant to high levels of erythromycin were arbitrarily selected for further analyses.

\section{B. Purification of EC-SOD from Culture Medium}

L. casei CCRC10679transformants were cultured at $37^{\circ} \mathrm{C}$ in 2-L fillister-type flasks containing $500 \mathrm{ml}$ of MRS broth. Four liters of culture medium were concentrated and partially purified by stirred-cell ultrafiltration (YM-10, Amicon, Danvers, MA, USA). The precipitate was resuspended in $0.2 \mathrm{M} \mathrm{KH}_{2} \mathrm{PO}_{4}$ and $\mathrm{K}_{2} \mathrm{HPO}_{4} \cdot 3 \mathrm{H}_{2} \mathrm{O}(\mathrm{pH} 7.5)$ and dialyzed against the same buffer. The desalted fractions were passed through a HiPrep ${ }^{\mathrm{TM}} 16 / 10$ Heparin FF column and then separated by fast protein liquid chromatography (FPLC) (AKTA purifier 10, Amersham Pharmacia Biotech., Piscataway, NJ, USA) for large-scale purification [18], [19].The fractions containing immunoreactive EC-SOD were pooled and concentrated using a Centriplus system (Millipore, Bedford, MA, USA).

\section{Immunoblot Analysis of EC-SOD Protein from Cell Pellets and Supernatants}

Cell pellets were lysed using lysis buffer [25 mMTris$\mathrm{HCl}$ (pH 8.0); 10 mM PMSF; 2 mM EDTA; 50 mM glucose] and a FRENCH ${ }^{\circledR}$ press $(4,000$ psi; Thermo Fisher Scientific, Waltham, MA, USA). To assay the extracellular secreted human EC-SOD, the culture medium was collected, filtered (Centriprep-10, Amicon, Danvers, MA, USA), and resolved by $12 \%$ SDS-PAGE. Proteins were electro-transferred from the gel to a nitrocellulose membrane [20]. The recombinant EC-SOD protein was detected using a mouse-anti-human EC-SOD antibody (1:3000 dilution) and a goat-anti-mouse IgG secondary antibody conjugated to horseradish peroxidase (1:10,000 dilution; Santa Cruz Biotech. Inc., Santa Cruz, CA, USA). The immunoblot was developed using anenhanced chemiluminescence (ECL) detection system (Amersham Pharmacia Biotech.). The amount of secreted EC-SOD was determined quantitatively using a previously described enzyme-linked immunosorbent assay (ELISA) [21].

\section{NBT and WST Assays for Enzymatic Activity of EC- $S O D$}

The EC-SOD antioxidant activity was determined by the nitrobluetetrazolium (NBT) method, as described previously [22]. Under fluorescent illumination, the gel uniformly emits blue light except where activeEC-SOD is present. Amicrotiter plate assay using a water-soluble tetrazolium (WST-1) system was used to quantify EC-SOD activity (SOD Assay Kit-WST; Dojindo Laboratories, Kumamoto, Japan) with bovine erythrocyte SOD1 (Sigma) as a standard. Aliquots of the solutions were immediately pipetted into 96well flat-bottom microtiter plates containing three empty blanks, a range of concentrations of the SOD standard, and a range of concentrations of each Heparin-purified EC-SOD sample. Rates of WST-1 reduction were measured at $\mathrm{OD}_{450}$ with a microplate reader [4]. Inhibition curves were determined for each EC-SOD solution, and the activity of each was calculated by comparing its $50 \%$ inhibition concentration $\left(\mathrm{IC}_{50}\right)$ to that of the standard for SOD. All ECSOD activities were measured in triplicate. The data were reproducible within a $10 \%$ deviation.

\section{E. Statistical Analysis}

All of the datawereanalyzed by Student's t-test. Differences between means were considered statistically significant at $* P<0.05$.

\section{RESUlts}

\section{A. Cloning and Introduction of theHuman EC-SOD Gene into L. casei CCRC10679}

A $0.7-\mathrm{kb}$ fragment of the full-length hsod3cDNA encoding human EC-SOD polypeptide was isolated from a human aortic smooth muscle cDNA library. The hsod3cDNA clone was constructed with the 18-aa signal peptide on its N-terminus (Fig. 1 (A) ). After introducing the EC-SOD gene into L. casei CCRC10679, an erythromycinresistant gene was used as the selectable marker for 
screening. The 18-aa signal peptide (Fig. 1 (B) ) allowed proper processing of the heterologously expressed precursor protein and release of the mature EC-SOD protein into the culture medium.

\section{B. Identification of Multi-Copy Genes from the EC-SOD Expression Cassette in L. casei CCRC10679}

(A)

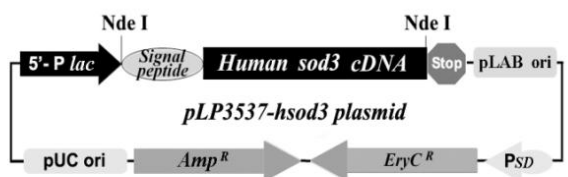

(B)

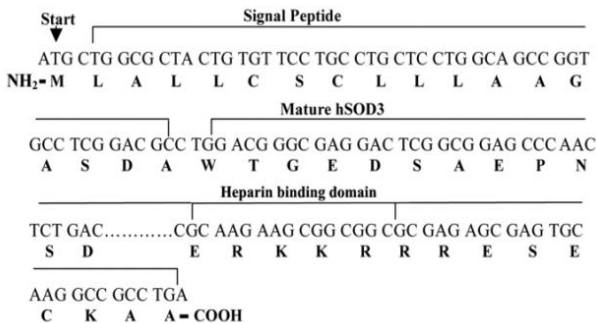

(C)

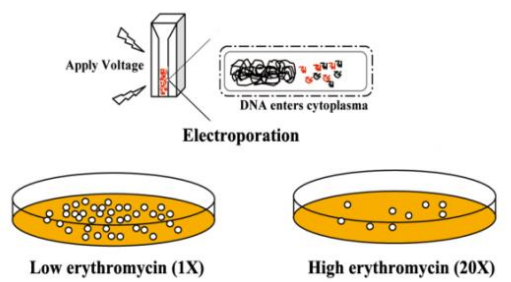

(D)

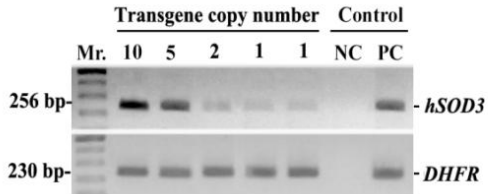

Fig. 1. Structural map and sequence of the recombinant Lactobacillus casei expressionconstruct. (A) Construction of the recombinant human sod3 expression plasmid pLP3537-hSOD3. The hSOD3 cDNA fragment was amplified by PCR and cloned into the Nde I sites of the pLP3537 vector under the control of the Lac promoter. The pLP3537 plasmid is a shuttle vector that utilizes both amplicillin (Amp)- and erythromycin (EryC)resistant genes as selectable markers. (B)Generation of the recombinant EC-SOD peptide. The lower line shows the predicted amino acid sequences for the N-terminal signal peptide (18-aa), the mature EC-SOD peptide, and the heparin binding domain. (C) Plasmid DNA transformation by electroporation. The transformants were selected using different concentrations (1X to 20X) of erythromycin antibiotics. (D) Identification of multi-copy insertions of the hSOD3 expression cassette in $L$. caseiCCRC10679 cells by semi-quantitative PCR. The housekeepingdihydrofolatereductase $(D H F R)$ gene was used as an internal control for gene copy quantification.

Among several hundred transformants isolated through primary screening with $1 \times$ erythromycin $(5.0 \mu \mathrm{g} / \mathrm{ml}), 200$ colonies were rescreened to identify seven multi-copy transformations. These transformants were detected by their resistance to higher concentrations of erythromycin $(25,50$, and $100 \mu \mathrm{g} / \mathrm{ml}$ ). Single copy transformants survived at low levels of erythromycin (1XEryC) but not at higher levelsof EryC (e.g., 20X) (Fig. 1 (C) ). A few transformants with multi-copy insertions (10 copies, 5 copies, or 2 copies per cell) of the EC-SOD expression cassette grew on the 20XEryC selection plate. Their copy numbers were verified by semi-quantitative PCR, as shown in Fig. 1 (D). These clones were selected for further protein expression, purification, and functional assays.

\section{Production and Purification of Human EC-SOD \\ Protein in L. casei CCRC10679 Culture Medium}

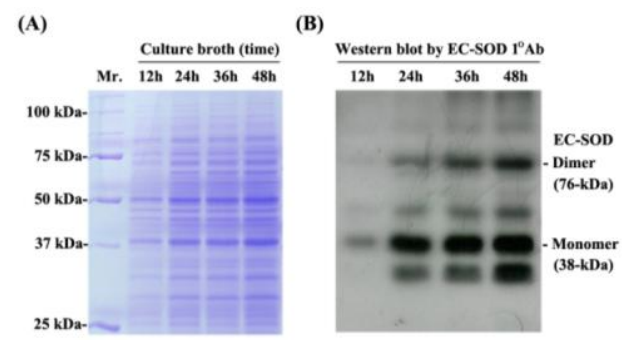

(C)

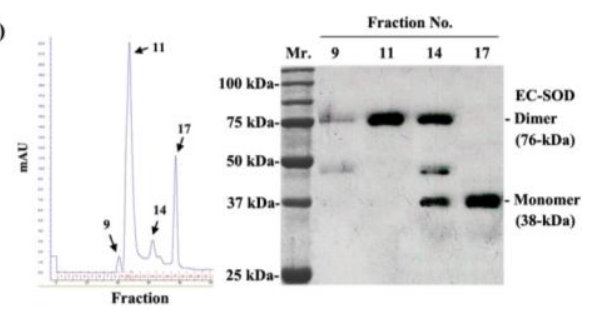

Fig. 2. Expression and purification of the recombinant human ec-Sod from transformed $l$. CASEI. (A) Analysis of the secreted protein in the transformed $L$. casei culture brothat different harvest times (12, 24, 36, and 48 hours)by 13\% SDS-PAGE. (B)Western blot analysis of recombinant human EC-SOD protein using a rabbit anti-human EC-SOD monoclonal antibody. The molecular weights of $38-$ and $76-\mathrm{kDa}$ represent EC-SOD monomers and dimers, respectively.(C) Purification of human EC-SODby fast protein liquid chromatography (FPLC) withaheparin affinity column. The purity and molecular weight of the purified EC-SOD was confirmed by $13 \%$ SDS-PAGE.

TABLE I: EC-SOD PROTEIN ACTIVITY AND YIELD DURING THE PURIFICATION PROCESSES

\begin{tabular}{lcccc}
\hline $\begin{array}{c}\text { Purification } \\
\text { steps }\end{array}$ & $\begin{array}{c}\text { Total } \\
\text { protein } \\
\left(\mathrm{mg}^{-1} \mathrm{ml}^{-1}\right)\end{array}$ & $\begin{array}{c}\text { Total } \\
\text { activity } \\
\left(\mathrm{U} \mathrm{ml}^{-1}\right)\end{array}$ & $\begin{array}{c}\text { Relative } \\
\text { activity } \\
\left({\left.\mathrm{U} \mu \mathrm{g}^{-1}\right)}^{-1}\right.\end{array}$ & $\begin{array}{c}\text { Yield } \\
(\%)\end{array}$ \\
\hline $\begin{array}{c}\text { Cell free extract from } \\
\text { hSOD3/L. casei }\end{array}$ & 11.4 & 34 & 2982 & 100 \\
$\begin{array}{c}\text { Hiprep 16/10 } \\
\text { Heparin column }\end{array}$ & 12.4 & 32 & 2851 & 94.1 \\
\hline $\begin{array}{l}\text { One unit of hSOD3 activity was defined as the amount of enzyme that could give } \\
50 \% \text { inhibition by WST-1 assay, }\end{array}$
\end{tabular}

L. casei/hSOD3transformants were grown to an $\mathrm{OD}_{600}$ of 3 in MRS medium. Aliquots of the culture broth were taken every $12 \mathrm{~h}$ for $48 \mathrm{~h}$. The expression level and accumulation of EC-SOD protein in the transformed L. casei CCRC10679 cells were significantly elevated as shown in Fig. 2 (A) for SDS-PAGE and Fig. 2 (B) for western blot analysis. The highest level of EC-SOD expression occurred $48 \mathrm{~h}$ after incubation. EC-SOD secretion, determined by measuring the levels of a $38-\mathrm{kDa}$ protein in cell lysates from $L$. casei CCRC10679 culture, attributed to the presence of the 18-aa signal peptide. EC-SOD protein dimers (76-kDa) werealso found in the FPLC purified fractions, as shown in Fig. 2 (B) and Fig. 2 (C).

\section{AntioxidantActivity of Purified Recombinant Human EC-SOD from L. casei CCRC10679 Supernatants}

Purified fractions containing EC-SOD monomers and dimers from the cultured $L$. casei CCRC10679 transformants were concentrated, separated on non-denaturing polyacrylamide gels and assayed by NBT staining for SOD activity (Fig. 3). A significant level of SOD activity was detected in the monomeric EC-SOD fraction (No. 17). A 
higher level of SOD activity was detected in the dimeric EC-SOD fraction (No. 11). The culture medium from $L$. casei CCRC10679 transformed with an empty vector was used as a negative wild-type (Wt) control.

Recombinant EC-SOD activity was determined using a WST-1 microtiter quantitative assay. The EC-SOD derived from the transformants was purified through a HiPrep heparin affinity column byfast protein liquid chromatography (FPLC). The standard inhibition curve was plotted by measuring the serial concentrations of bovine SOD1 in a total reaction volume of $200 \mu$ l. As shown in Table I, the purified EC-SOD specific activity was 2,982 $\mathrm{U} / \mu \mathrm{g}$ in the crude extract and $2,851 \mathrm{U} / \mu \mathrm{g}$ after the heparin purification. The purification yield was $94.1 \%$.

\section{E. Growth Rates of EC-SOD-Expressing Transformants and Wild Type L. casei CCRC10679}

The transformed L. casei CCRC10679 cultures were grown for 2 days to evaluate growth performance in the late exponential and stationary phases. Growth curves were constructed by measuring the growth of the transformed L.casei cells every $6 \mathrm{~h}$ (Fig. 4). By $12 \mathrm{~h}$, the $\mathrm{OD}_{600}$ of the cells expressing EC-SOD exceeded that of the wild type strains $(P<0.05)$. The growth rate of the EC-SODexpressing $L$. caseitransformants accelerated during the late logarithmic phase.The maximal transformedcell concentration $\left(\mathrm{OD}_{600}=23\right)$ was reached at $48 \mathrm{~h}$ incubation. The wild type culture displayed slower logarithmic phase growth and reached the stationary phase $\left(\mathrm{OD}_{600}=18\right)$ at $36 \mathrm{~h}$ of incubation.

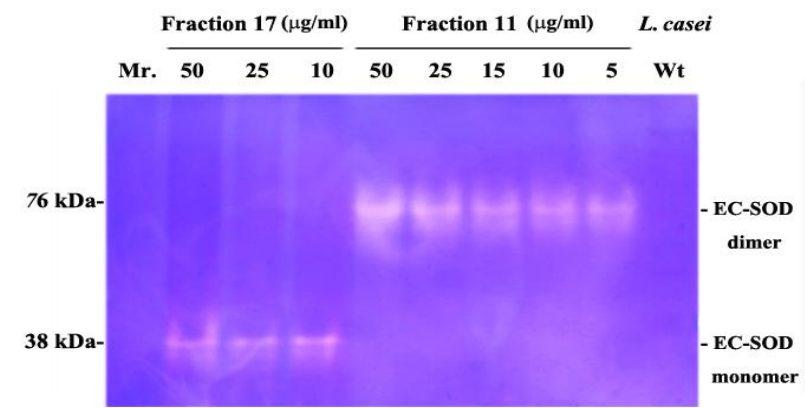

Fig. 3. Sod activity as measured by NBT GEL electrophoresis of the purified EC-SODMONOMER (fraction no. 17) and the EC-SODDIMER (fraction no. 11). Purified monomeric and dimeric EC-SOD proteins were resolved on a $10 \%$ non-denaturing polyacrylamide gel. The first three lanes contain different concentrations $(50,25$, and $10 \mu \mathrm{g} / \mathrm{ml})$ of monomeric ECSOD. The next five lanes contain different concentrations $(50,25,15,10$, and $5 \mu \mathrm{g} / \mathrm{ml}$ ) of dimeric EC-SOD. The last lane is non-transformed $L$. caseiused as a wild type (Wt) control.

\section{DISCUSSION}

An important feature of EC-SOD is its high affinity for heparin, which is thought to anchor EC-SOD to the cell surface and the extracellular matrix. The affinity of purified EC-SOD for heparin can be classified as no affinity (type A), moderate affinity (type $\mathrm{B}$ ), or high affinity (type $\mathrm{C}$ ). This heterogeneous heparin affinity resultsfrom proteolysis of the heparin-binding domain. Regulation of this proteolytic event may be an important control point in modulating EC-SOD activity in the extracellular matrix[23]-[26]. In 2002, He et al. [27] used E.coliwith abaculovirus expression system to produce mature human EC-SOD. However, the expression system resulted in theformationof inclusion bodies. Therefore, denaturation followed by renaturationwas required to obtain sufficient EC-SOD antioxidant activity. Xiang et al. [28] established a food-grade host/vector system in L. lactis to express human $\mathrm{Cu} / \mathrm{Zn}$ SOD (SOD1).

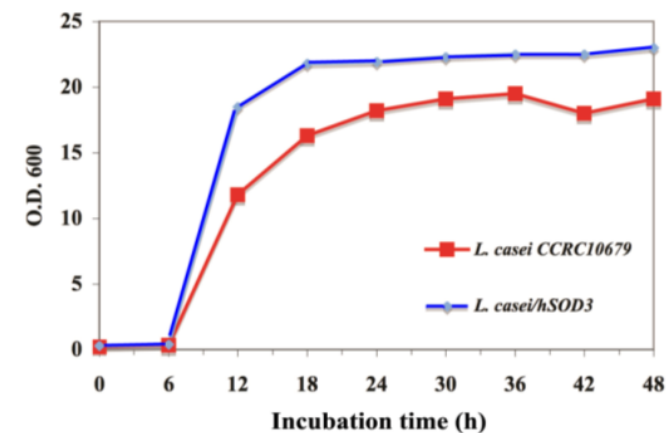

Fig. 4. Cell growth of wild type L. Casei and ec-Sod transformants. Cell growth was measured for wild type $L$. casei CCRC10679 and transformed

L. casei/hSOD3 cells every 6 hours for 48 hours. The assays were performed in triplicate.

In our previous study, we used a $P$. pastoris yeast culture system [4] to obtain high levels of EC-SOD expression in cell pellets and culture medium. This wasthe first report of human EC-SOD expression in a eukaryotic cell system. In the present study, we examined the effect of simulated gastric and small intestine transit on the viability of potentially probiotic LAB, L.casei CCRC10679. Our constructs contained the full-length human SOD3cDNAsequence with the $\mathrm{N}$-terminal sequence of mature EC-SOD preceded by an 18-residue signal peptide. Because bacterial expression systems rarely recognize eukaryote-derived signal peptides, we inserted NdeI fragments encoding mature EC-SOD peptides into the pLP3537expression plasmidcontaining an erythromycinresistant gene for selection of strains capable of expressing high levels of exogenous protein (Fig. 1).

According to the time-course expression assay, the transformed $L$. casei/hSOD3cells can produce high levels ofrecombinant human EC-SOD protein in culture broth,as detected by western blottingof samples collected from $24 \mathrm{~h}$ to 48 hof culture.In previous reports, recombinant EC-SOD protein displayed a series of monomer bandsbetween 26.7$\mathrm{kDa}$ and38-kDa [29]-[32]. We identified two major products at $38-\mathrm{kDa}$ and $76-\mathrm{kDa}$ corresponding to the monomer and the dimer, respectively (Fig. 2). The NBT activity assay showed that dimeric EC-SOD exhibits higher antioxidant activity than the monomeric EC-SOD following nativePAGE (Fig. 3). Reactive oxygen species (ROS) can affect cell life span; for example, in fungi, mutants defective in ROS detoxification have limited viability during the stationary phase [33]. We found that L. caseitransformants expressing EC-SOD exhibited higher cell densitiesthan the wild type L. caseicells during the stationary phase (Fig. 4). This result may be due to an acquired antioxidant ability that reduces the effect of ROS generation during the late exponential and stationary cell growth stages.

In conclusion, we developed an L. casei CCRC10679 cell system forexpression and secretion ofrecombinant human EC-SOD protein. The antioxidant activity of therecombinant EC-SOD was 2,851 U/ $\mu \mathrm{g}$ following heparin purification. Further investigation of recombinant EC-SOD production 
by $L$. casei is required to determine if this enzyme has potential clinical, food or feedstuff applications.

\section{ACKNOWLEDGMENTS}

The authors would like to thank Dr. Jeffrey Conradfor critically reading the manuscript. This research was supported in part by grantNSC-100-2313-B-005-012 from the National Science Council and the Ministry of Education, Taiwan, Republic of China, under the ATU plan.

\section{REFERENCES}

[1] S. L. Marklund, "Human copper-containing superoxide dismutase of high molecular weight," in Proc. Natl. Acad. Sci., USA, vol. 79, pp. 7634-7638, Dec. 1982

[2] R. A. Weisiger and I. Fridovich, "Mitochondrial superoxide dismutase: site of synthesis and intra-mitochondrial localization," $J$. Biol. Chem., vol. 248, pp. 4793-4796, Jul. 1973 .

[3] T. D. Oury, J. D. Crapo, Z. Valnickova, and J. J. Enghild, "Human extracellular superoxide dismutase is a tetramer composed of two disulphide-linked dimers: a simplified, high-yield purification of extracellular superoxide dismutase," Biochem. J., vol. 317, pp. 51-57, Jul. 1996.

[4] H. L. Chen, C. C. Yen, T. C. Tsai, C. H. Yu, Y. J. Liou, Y. W. Lai, M. L. Wang, and C. M. Chen, "Production and characterization of human extracellular superoxide dismutase in the methylotrophic yeast Pichiapastoris," J. Agric. Food Chem., vol. 54, pp. 8041-8047, Oct. 2006.

[5] T. D. Oury, B. J. Day, and J. D. Crapo, "Extracellular superoxide dismutase: a regulator of nitric oxide bioavailability," Lab. Invest., vol. 75, pp. 617-636, Nov. 1996.

[6] T. D. Oury, L. Y. Chang, S. L. Marklund, B. J. Day, and J. D. Crapo, "Immunocytochemical localization of extracellular superoxide dismutase in human lung," Lab. Invest., vol. 70, pp. 889-898, Jun. 1994.

[7] V. L. Kinnula and J. D. Crapo, "Superoxide dismutases in malignant cells and human tumors," Free Radic. Biol. Med., vol. 36, pp. 718 744, Mar. 2004.

[8] C. C. Yen, S. H. Yang, C. Y. Lin, and C. M. Chen, "Stem cells in the lung parenchyma and prospects for lung injury therapy," Eur. J. Clin. Invest., vol. 36, pp. 310-319, May 2006.

[9] C. C. Yen, Y. W. Lai, H. L. Chen, C. W. Lai, C. Y. Lin, W. Chen, Y. P. Kuan, W. H. Hsu, and C. M. Chen, "Aerosolized human extracellular superoxide dismutase prevents hyperoxia-induced lung injury," PLoS One, vol. 6, pp. e26870, Oct. 2011.

[10] M. O. Jeroudi, C. J. Hartley, and R. Bolli, "Myocardial reperfusion injury: role of oxygen radicals and potential therapy with antioxidants," Am. J. Cardiol., vol. 73, pp. 2-7, Mar. 1994.

[11] J. Silva, A. S. Carvalho, P. Teixeira, and P. A. Gibbs, "Bacteriocin production by spray-dried lactic acid bacteria," Lett. Appl. Microbiol., vol. 34, pp. 77-81, Feb. 2002

[12] C. M. Pilar, A. Samuel, B.Karola, D. M. Trinidad, P. Ananias, and B. V. Jorge, "Current amplications and future trends of lactic acio bacteria and their bacteriocins for the biopreservation of aquatic food products," Food Bioprocess Technol., vol. 1, pp. 43-63, 2008.

[13] H. L. Chen, L. C. Wang, C. H. Chang, C. C. Yen, W. T. K. Cheng, S C. Wu, C. M. Hung, M. F. Kuo, and C. M. Chen, "Recombinan porcine lactoferrin expressed in the milk of transgenic mice protects neonatal mice from a lethalchallenge with enterovirus type 71," Vaccine, vol. 26, pp. 891-898, Feb. 2008.

[14] H. L. Chen, J. Y. Huang, T. W. Chu, T. C. Tsai, C. M. Hung, C. C. Lin, F. C. Liu, L. C. Wang, Y. J. Chen, M. F. Lin, and C. M. Chen, "Expression of VP1 protein in the milk of transgenic mice: As a potential oral vaccine against for enterovirus 71 strain infection,' Vaccine, vol. 26, pp. 2882-2889, Jun. 2008.

[15] Y. T. Tung, H. L. Chen, C. C. Yen, P. Y. Lee, H. C. Tsai, M. F. Lin, and C. M. Chen, "Bovine lactoferrin inhibits lung cancer growth through suppression of both inflammation and expression of vascular endothelial growth factor," J. Dairy Sci., vol. 94, pp. 2095-2106, Apr. 2013.

[16] F. C. Liu, H. L. Chen, W. Lin, Y. T. Tung, C. W. Lai, A. L. Hsu, and C. M. Chen, "Application of porcine lipase secreted by pichiapastoris to improve fat digestion and growth performance of postweaning piglets," J. Agric. Food Chem., vol. 58, pp. 3322-3329, Mar. 2010

[17] H. L. Chen, C. C. Yen, C. Y. Lu, C. H. Yu, and C. M. Chen, "Synthetic porcine lactoferricin with 20-residue peptide exhibits antimicrobial activity against Escherichia coli, Staphylococcus aureus and Candida albicans," J. Agri. Food Chem., vol. 54, pp. 3277-3282, May 2006

[18] H. L. Chen, Y. W. Lai, C. C. Yen, Y. Y. Lin, C. Y. Lu, S. H. Yang, T C. Tsai, Y. J. Lin, C. W. Lin, and C. M. Chen, "Production of recombinant porcine lactoferrin exhibiting antibacterial activity in methylotrophic yeast, Pichiapastoris," J. Mol.Microbiol.Biotechnol., vol. 8, pp. 141-149, Mar. 2004

[19] C. M. Hung, S. C. Wu, C. C. Yen, M. F. Lin, Y. W. Lai, Y. T. Tung, H. L. Chen, and C. M. Chen, "Porcine lactoferrin as feedstuff additive elevates avian immunity andpotentiates vaccination," Biometals, vol. 23 , pp. $579-587$, Jun. 2010

[20] H. L. Chen, Y. W. Lai, C. S. Chen, T. W. Chu, W. Lin, C. C. Yen, M. F. Lin, M. Y.Tu, and C. M. Chen, "Probiotic Lactobacillus casei expressing human lactoferrin elevates antibacterial activity in the gastrointestinal tract," Biometals, vol. 23, pp. 543-54, Jun. 2010.

[21] C. J. Shen, W. T. K. Cheng, S. C. Wu, H. L. Chen, T. C. Tsai, S. H. Yang, and C. M. Chen, "Differential differences in methylation status of putative imprinted genes among cloned swine genomes," PLoS One, vol. 7, pp. e32812, Feb. 2012

[22] A. V. Peskin and C. C. Winterbourn, "A microtiter plate assay for superoxide dismutase using a water-soluble tetrazolium salt (WST-1)," Clin. Chim. Acta., vol. 293, pp. 157-166, Mar. 2000.

[23] K. Karlsson and S. L. Marklund, "Extracellular superoxide dismutase in the vascular system of mammals," Biochem. J., vol. 255, pp. 223 228, Oct. 1988.

[24] J. Sandstrom, K. Karlsson, T. Edlud, and S. L. Marklud, "Heparinaffinity patterns and composition of extracellular superoxide dismutase in human plasma and tissues," Biochem. J., vol. 294, pp. 853-857, Sep. 1993

[25] J. Sandstrom, L. Carlsson, S. L. Marklund, and T. Edlund, "The heparin-binding domain of extracellular superoxide dismutase $\mathrm{C}$ and formation of variants with reduced heparin affinity," J. Biol. Chem., vol. 267, pp. 18205-18209, Sep. 1992.

[26] H. Ohta, T. Adachi, and K. Hirano, "The nature of heterogeneous components of extracellular superoxide dismutase purified from human umbilical cords," Free Radic. Biol. Med., vol. 15, pp. 151-158, Aug. 1993.

[27] H. J. He, Q. S. Yuan, G. Z. Yang, and X. F. Wu, "High-level expression of human extracellular superoxide dismutase in Escherichia coli and insect cells," Protein Expr. Prif., vol. 24, pp. 1317, Feb. 2002.

[28] H. Xiang, W. Wei, and H. Tan, "Food-grade expression of human glutathione S-transferase and $\mathrm{Cu} / \mathrm{Zn}$ superoxide dismutase in Lactococcuslactis," Biomol. Eng., vol. 20, pp. 107-112, Mar. 2003.

[29] A. Edlund, T. Edlund, K. Hjalmarsson, S. L. Marklund, J. Sandström, M. Strömqvist, and L. Tibell, "A non-glycosylated extracellular superoxide dismutase variant," Biochem. J., vol. 288, pp. 451-456, Dec. 1992

[30] L. Tibell, K. Hualmarsson, T. Edlund, G. Skogman, A. Engstrom, and S. L. Marklund, "Expression of human extracellular superoxide dismutase in Chinese hamster ovary cells and characterization of the product," in Proc. Natl. Acad. Sci., USA, vol. 84, pp. 6634-6638, Oct. 1987.

[31] L. A. Tibell, E. Skarfatad, and B. H. Jonsson, "Determination of the structural role of the $\mathrm{N}$-terminal domain of human extracellular superoxide dismutase by use of protein fusions," Biochim. Biophys. Acta., vol. 1292, pp. 47-52, Jan. 1996.

[32] K. Williams, J. Frayne, E. A. McLaughlin, and L. Hall, "Expression of extracellular superoxide dismutase in the human male reproductive tract, detected using antisera raised against recombinant protein," Mol. Hum. Reprod., vol. 4, pp. 235-242, Mar. 1998.

[33] S. Melov, "Mitochondrial oxidative stress: Physiologic consequences and potential for a role in aging,"Ann. N.Y. Acad. Sci., vol. 908, pp. 219-225, Jun. 2000.

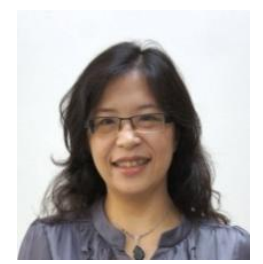

Hsiao-Ling Chen was born at Taipei, Taiwan, in 1968. She was awarded a Ph.D. degree in animal sciences in 2000 from the National Taiwan University, Taiwan. She moved to Missouri University as a Postdoc fellow in 2001-2002. From Aug. 1, 2002 to now, she worked as a Professor at the Department of Molecular Biotechnology and also the Department of Bioresources, Da-Yeh University. Her primary interests focus on functional foods development and biotechnology. More than 50 papers has been published in SCI journals from her research works and also owned 8 innovation patents in USA, Taiwan, European, and China. 